\title{
Day-to-day repeatability of the Pulse Time Index of Norm
}

\author{
This article was published in the following Dove Press journal: \\ Medical Devices: Evidence and Research \\ 27 February 2014 \\ Number of times this article has been viewed
}

\author{
Igor N Posokhov' \\ Aleksandra O Konradi ${ }^{2}$ \\ Eugeny $V$ Shlyakhto ${ }^{2}$ \\ Oleg $\vee$ Mamontov ${ }^{2}$ \\ Artemy $\vee$ Orlov $^{3}$ \\ Anatoly N Rogoza ${ }^{4}$ \\ 'Hemodynamic Laboratory Ltd, \\ Nizhniy Novgorod, ${ }^{2}$ Almazov Federal \\ Heart, Blood and Endocrinology \\ Centre, Saint Petersburg, ${ }^{3}$ Department \\ 65 Competitive System Analysis, \\ National Research Nuclear University, \\ Moscow, ${ }^{4}$ Cardiology Research \\ Center, Moscow, Russia
}

\begin{abstract}
The pulse wave velocity (PWV) threshold for hypertensive target organ damage is presently set at 10 meters per second. New 24-hour monitors (eg, BPLab ${ }^{\circledR}$ and Vasotens ${ }^{\circledR}$ ) provide several PWV measurements over a period of 24-72 hours. A new parameter, ie, the Pulse Time Index of Norm (PTIN), can be calculated from these data. The PTIN is defined as the percentage of a 24-hour period during which the PWV does not exceed 10 meters per second. The aim of the present study was to test the new PTIN for clinical feasibility using day-to-day repeatability analysis. Oscillometrically generated waveform files $(n=85)$, which were previously used for research studies, were reanalyzed using the new 2013 version software of the Vasotens technology program, which enables calculation of PTIN. The intraclass correlation coefficient was 0.98 and Cronbach's alpha was 0.97 , indicating that the PTIN has excellent day-to-day repeatability and internal consistency. The present results show adequate repeatability, and PTIN assessment using the Vasotens technology appears to be feasible.
\end{abstract}

Keywords: pulse wave velocity, ambulatory, 24-hour, monitoring, Pulse Time Index of Norm, arterial stiffness

\section{Introduction}

The pulse wave velocity (PWV) measurement is a method of assessing arterial stiffness and is important in evaluation of cardiovascular risk. Arterial stiffness is the ability of an artery to expand and contract in response to pressure changes. The consequence of reduced compliance and distensibility that describes vessel stiffness is an increased propagation velocity of the pressure pulse along the arterial tree, known as pulse wave velocity (PWV), and relates to arterial distensibility. ${ }^{1}$ Arterial stiffness is measured by PWV and is an independent predictor of cardiovascular morbidity and mortality in hypertensive patients, those with end-stage renal disease or type 2 diabetes, and elderly populations. ${ }^{2}$

The PWV measurement has been adopted extensively for routine clinical use, as illustrated by its inclusion as a recommended test in the 2013 European Society of Hypertension/European Society of Cardiology guidelines for managing hypertension. ${ }^{3}$ The PWV threshold as an indicator of hypertensive target organ damage was set at 10 meters per second. ${ }^{3-5}$

Pulse wave registration at two sites is traditionally used to obtain the distance (in meters) and the time interval (in seconds) needed for the PWV (in meters per second) equation. The standard for PWV is simultaneous waveforms recorded invasively from just above the aortic valve and the aortic bifurcation. The method most commonly used to estimate aortic PWV relies on simultaneous measurement of waveforms recorded 
by carotid and femoral artery applanation tonometry. ${ }^{6}$ Magnetic resonance imaging and ultrasound techniques provide additional information on regional differences in aortic stiffness. $^{\text {? }}$

Cuff-based methods such as Vasotens ${ }^{\circledR}$, (used in BPLab $^{\circledR}$-Vasotens ${ }^{\circledR}$ complex; Petr Telegin Company, Nizhny Novgorod, Russia) derive PWV values from oscillometric measurements of the brachial artery waveform. These simple techniques make widespread clinical PWV measurements a realistic possibility in the near future. ${ }^{7}$ The principle of these methods has been described well previously. ${ }^{8}$

Notably, systems for PWV measurements are usually integrated into ambulatory blood pressure monitoring (ABPM) systems that provide not only one PWV measurement but also several PWV measurements over a period of 24-72 hours. This novel 24-hour pulse wave analysis led to the development of a new calculation, ie, the Pulse Time Index of Norm (PTIN), provided by Vasotens technology. The PTIN optimizes the approach to antihypertensive therapy. ${ }^{9}$ Vasotens technology is an innovative method that is used for pulse wave analysis based on oscillometric blood pressure measurements using the BPLab ${ }^{\circledR}$ ABPM system, which has been previously validated as an accurate and feasible ambulatory blood pressure and vascular indices monitoring device. ${ }^{9-12}$ The PTIN is defined as the percentage of a 24-hour period during which the PWV does not exceed 10 meters per second. No previous research exists on the reliability or day-to-day repeatability of the PTIN.

A specific feature of the Vasotens technology was used in the present study. This technology processes the oscillometrically generated waveform files, which are received, digitized, and stored in computer memory by the BPLabWin ${ }^{\circledR}$ (Petr Telegin Company) software. Data processing can be performed either during or at any time after ABPM analysis. The above features allow establishment of the BPLab Vasotens registry as a project with dozens of small groups, and its purpose is to provide joint solutions for various scientific problems. Thus, the aim of the present work was to test the new PTIN for clinical feasibility using day-to-day repeatability retrospective analysis.

\section{Materials and methods Baseline characteristics}

Overall, 85 oscillometrically generated waveform files that had previously been used in ABPM studies of greater than 2 days (>48 hours) were reanalyzed using the new 2013 version software for the Vasotens technology program.
The waveform files chosen for the present study contain successful measurements of PWV for at least 14 wake periods and seven sleep periods. Additionally, we performed quality control by visual assessment of the curves in the Vasotens clinical report screen and by detection of artifacts. An average of $47 \pm 6.5$ successful readings was recorded during the monitoring period and an average of $0.04 \%$ of artifacts was recorded.

The original exclusion criteria used to select patients in the registry were as follows: younger than 19 years of age, blood testing and electrocardiographic abnormalities, body mass index greater than $27.5 \mathrm{~kg} / \mathrm{m}^{2}$, and impaired glucose tolerance (for normotensive patients); and less than 19 years of age and a body mass index greater than $27.5 \mathrm{~kg} / \mathrm{m}^{2}$ (for hypertensive patients).

Table 1 shows the baseline characteristics of patients whose waveform files were used. All studies in which data were reanalyzed were authorized by the local ethics commissions. All enrolled patients provided their written informed consent.

\section{Vasotens technology}

The new version of the Vasotens software differs from the old version in that the new one has the automatic PTIN calculation. The method of PTIN calculation consists of assessing pulse waves at the brachialis muscle in ambulatory (ie, 24-hour) measurement mode. An oscillometric type of registration method using the $\mathrm{BPLab}^{\circledR}$ system for 24-hour monitoring was undertaken. The recordings are made using a conventional blood pressure cuff for adults. During the blood pressure measurement, the pressure waveforms in the cuff are registered, digitalized, and stored in the device while performing a step-by-step deflation. The distance for the PWV equation used in Vasotens was measured according to the manufacturer's requirements. The separa-

Table I Baseline characteristics of study patients

\begin{tabular}{ll}
\hline Male, $\mathrm{n}(\%)$ & $67(79)$ \\
Age, mean (SD) years & $47(17)$ \\
Height, mean (SD) cm & $169(12)$ \\
Weight, mean (SD) kg & $83(14)$ \\
SBP, mean (SD) mmHg & $140(2 \mathrm{I})$ \\
DBP, mean (SD) mmHg & $83(13)$ \\
Heart rate, mean (SD) bpm & $71(12)$ \\
Hypertension, $\mathrm{n}(\%)$ & $70(82)$ \\
Previous Ml or stroke, $\mathrm{n}(\%)$ & $7(8)$ \\
LVH, n (\%) & $14(16)$ \\
Renal disease, $\mathrm{n}(\%)$ & $2(2)$ \\
\hline
\end{tabular}

Abbreviations: DBP, diastolic blood pressure; SBP, systolic blood pressure; $\mathrm{MI}$, myocardial infarction; LVH, left ventricular hypertrophy; SD, standard deviation. 
tion and timing of the forward and reflected pulse waves were determined using a previously described automatic algorithm. ${ }^{8-10}$

\section{Statistical analysis}

We used BPStat software version 05.00.04 (BPLab) that enabled automatic tabulation of all indices of every measured waveform. MedCalc (MedCalc Software bvba, Ostend, Belgium) and Statistical Package for the Social Sciences (SPSS Inc., Chicago, IL, USA) software were used to calculate intraclass correlation coefficients and Cronbach's alpha to assess the day-to-day repeatability of the measurements. Limits of agreement were also calculated (mean difference $\pm 1.96 \times$ standard deviation), as described by Bland and Altman, whereby lower values indicate improved agreement between days. ${ }^{13}$ Cronbach's alpha is a coefficient of internal consistency ${ }^{14}$ and is used as an estimate of the reliability of any test. We considered internal consistency and intraclass correlation coefficients to be excellent if the coefficients were $\geq 0.9$, good if they were between 0.7 and 0.9 , and acceptable if they were between 0.6 and 0.7 .

\section{Results}

The PTIN calculation is illustrated in Figure 1. The waveform files from 85 patients with ABPM for longer than 2 days ( $>48$ hours) were used in the day-to-day repeatability analysis. The PTIN for the first and second 24-hour wake and sleep periods in each case was used to construct the BlandAltman diagram (Figure 2). Our study showed a Cronbach's alpha of 0.967 (Figure 2A), indicating excellent internal consistency of the 24-hour PTIN. Differences in the internal consistency of the wake PTIN and the sleep PTIN should be noted. However, the internal consistency of the PTIN was excellent for both wake (Cronbach's alpha 0.911, Figure 2B) and sleep (Cronbach's alpha 0.972, Figure 2C) periods.
Table 2 shows the PTIN and its day-to-day repeatability separately for normotensive and hypertensive patients. The data in the table indicate excellent intraclass correlation coefficients and Cronbach's alphas in hypertensive and hypotensive patients. The results are considered excellent for all periods, except the wake period in hypertensive patients, for which the results are considered good.

\section{Discussion}

In recent years, issues have arisen when estimating the PWV for ambulatory conditions. ${ }^{15}$ Performing multiple PWV measurements over time for a given patient would be more insightful than performing only a single PWV measurement. Approximately $90 \%$ of the monitoring period in normotensive patients and $60 \%$ of that in hypertensive patients are periods with normal PWV. A parallel of the potential usefulness of 24-hour PWV monitoring compared with ABPM is that diagnosis of hypertension has been based on clinical measurements of blood pressure. Recently, evidence of a reduction in misdiagnosis was reported in a cost-effectiveness study, and the ABPM method was recommended more extensively. ${ }^{16,17}$ First, PTIN was described in a study of patients with endstage renal disease. ${ }^{9}$ The mean PTIN in this group was $56.3 \%$ and depended on duration of the preoperative dialysis period and differences in age. In our study, we obtained similar PTIN results in hypertensive patients.

Although other devices do exist for 24-hour PWV measurement, only the Vasotens technology provides automatic calculation of PTIN. Oscillometric systems for PWV analysis that are integrated into ABPM systems have repeatedly been validated and studied for reliability and feasibility. ${ }^{10,15,18-20}$ However, if analysis of 24-hour PWV monitoring follows the same principles as those used for analysis of ABPM, ie, assessment of the time index, then the test quality will be determined in different ways from the above studies.

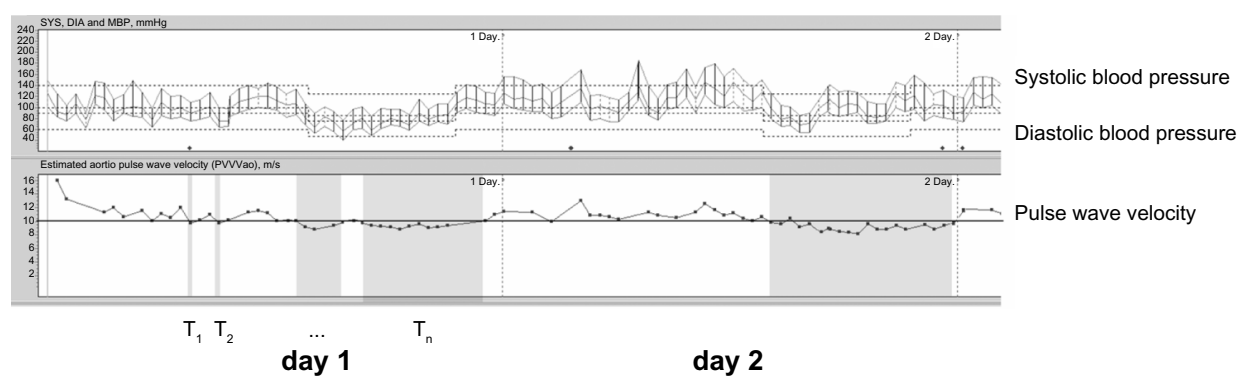

Figure I PTIN calculation principle.

Notes: TI, T2, and Tn are periods in which PWV does not exceed the threshold value of $10 \mathrm{~m} / \mathrm{s} . \mathrm{PTIN}, \%=(\mathrm{TI}+\mathrm{T} 2+\ldots+\mathrm{Tn}) / \mathrm{Tm} \cdot 100$, where Tm is the period or part of the period of monitoring. A PTIN of $41 \%$ (first day period) and a PTIN of $43 \%$ (second day period) are shown in the above example.

Abbreviations: PTIN, Pulse Time Index of Norm; PWV, pulse wave velocity. 

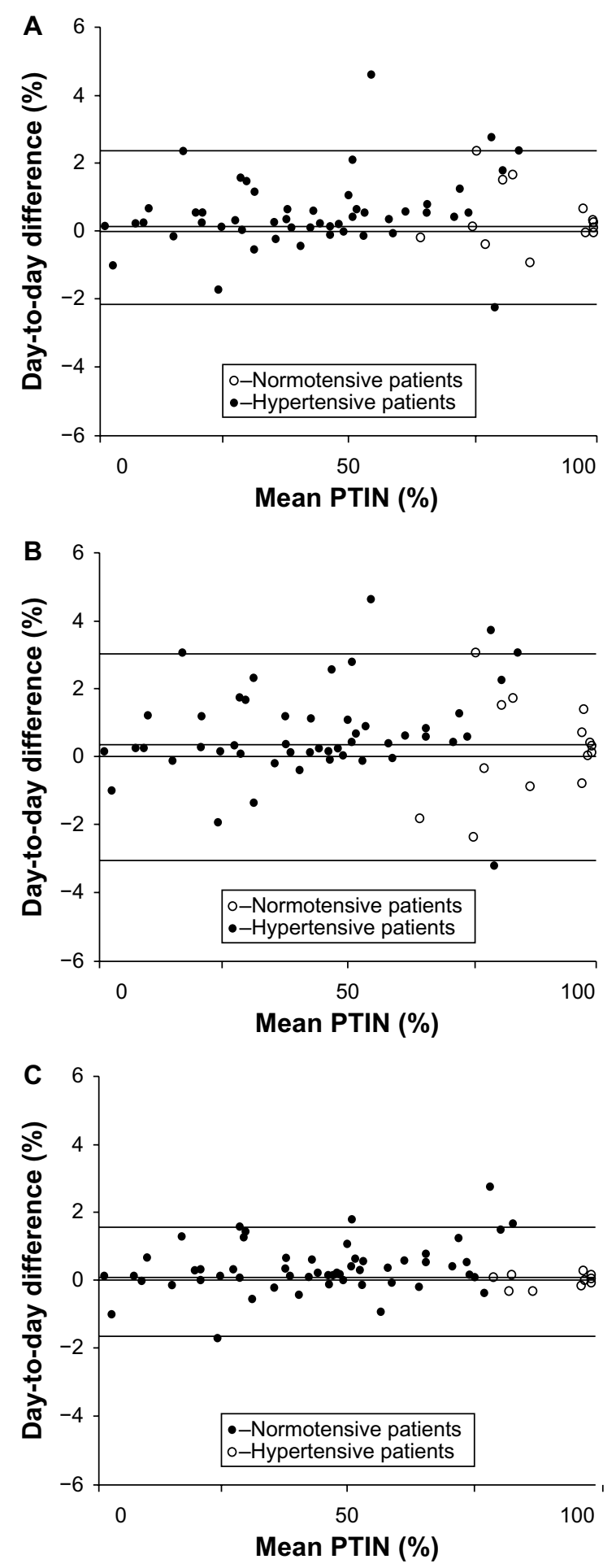

Figure 2 Day-to-day repeatability of the PTIN. Bland-Altman plots for (A) 24 hours and for (B) wake, and (C) sleep periods.

Abbreviation: PTIN, Pulse Time Index of Norm.

The main result of the present study is the excellent day-to-day repeatability, which is important because conclusions regarding significant alterations in aortic function and inclusion of a patient in a particular risk group are crucially dependent on the accuracy of PWV measurement.
Table 2 Pulse Time Index of Norm and its day-to-day repeatability in normotensive and hypertensive patients

\begin{tabular}{|c|c|c|c|c|c|c|}
\hline \multirow{2}{*}{$\frac{\text { Patients }}{\text { Periods }}$} & \multicolumn{3}{|c|}{ Normotensive } & \multicolumn{3}{|c|}{ Hypertensive } \\
\hline & 24-hour & Wake & Sleep & 24-hour & Wake & Sleep \\
\hline $\begin{array}{l}\text { Day I PTIN, } \\
\text { mean (\%) }\end{array}$ & 86.5 & 85.1 & 89.9 & 57.5 & 47.2 & 62.5 \\
\hline $\begin{array}{l}\text { Day } 2 \text { PTIN, } \\
\text { mean (\%) }\end{array}$ & 87.3 & 86.4 & 89.8 & 57.4 & 47.6 & 62.5 \\
\hline $\begin{array}{l}\text { Intraclass } \\
\text { correlation } \\
\text { coefficient }\end{array}$ & 0.98 & 0,91 & 0.99 & 0.95 & 0.91 & 0.98 \\
\hline $\begin{array}{l}\text { Limits of } \\
\text { agreement }\end{array}$ & 4,5 & 4,8 & $\mathrm{I}, \mathrm{I}$ & 4,7 & 5,1 & 3,6 \\
\hline $\begin{array}{l}\text { Cronbach's } \\
\text { alpha }\end{array}$ & 0.97 & 0.92 & 0.99 & 0.94 & 0.89 & 0.96 \\
\hline
\end{tabular}

Abbreviation: PTIN, Pulse Time Index of Norm.

Differences in the internal consistency of the wake PTIN and the sleep PTIN can be explained by the effect of the nocturnal pattern of PWV, as noted in other studies. ${ }^{9,15}$

Several limitations exist for this study. Logically, repeatability should be supplemented by reproducibility in order to describe reliability more completely, but this is methodologically difficult. We did not find a prototype study of the intraobserver reproducibility for 24-hour (ambulatory) indices. Thus, the present results show sufficient day-to-day repeatability, and PTIN assessment with the Vasotens technology appears to be feasible.

\section{Acknowledgment}

This work is published on behalf of all the BPLab-Vasotens registry collaborators. Members of the BPLab-Vasotens Registry Group are as follows: Hemodynamic Laboratory Ltd, Nizhniy Novgorod, Russia: Igor N Posokhov, Georgy D Nesterov; Universitätsklinikum Schleswig-Holstein, Campus Lübeck, Med Klinik II, Lübeck, Germany: Johannes Baulmann; Cardiology Research and Production Complex, Moscow, Russia: Anatoly N Rogoza; People's Friendship University of Russia, Medical Faculty, Moscow, Russia: Zhanna D Kobalava, Yulia V Kotovskaya; Almazov Federal Heart, Blood and Endocrinology Centre, Saint-Petersburg, Russia: Aleksandra O, Konradi, Eugeny V Shlyakhto, Oleg V Mamontov; Petrozavodsk State University, Petrozavodsk, Russia: Viktoria A Korneva, Tatyana Y Kuznetsova; 3rd Republican Hospital, Saransk, Russia: Natalya N Kulikova, Irina V Starchenkova; Department 65 Competitive system analysis, National Research Nuclear University MEPhI, Moscow, Russia: Artemy V Orlov; Chelyabinsk State Medical Academy, Chelyabinsk, Russia: Elena A Grigoricheva, Vitaly V Evdokimov; The hospital within the Russian Railroad 
Network, Chita, Russia: Evgeniya N Bryantseva, Vitaliy S Barkan, Vladimir V Gorbunov, Sergey A Alekseev.

\section{Disclosure}

BPLab ABPM systems were allocated to OM and AK who participated in a scientific competition (2008-2011) organized by the manufacturer (Petr Telegin Company). The BPstat software was made available to IP and AO by the manufacturer (Petr Telegin Company).

\section{References}

1. Nichols W, O'Rourke M, Vlachopoulos C. McDonald's Blood Flow in Arteries, Sixth Edition: Theoretical, Experimental and Clinical Principles. London, UK: Hodder Arnold; 2011.

2. Laurent S, Cockcroft J, Van Bortel L, et al. Expert consensus document on arterial stiffness: methodological issues and clinical applications. Eur Heart J. 2006;27:2588-2605.

3. Mancia G, Fagard R, Narkiewicz K, et al. 2013 ESH/ESC Guidelines for the management of arterial hypertension: the task force for the management of arterial hypertension of the European Society of Hypertension (ESH) and of the European Society of Cardiology (ESC). J Hypertens. 2013;31:1281-1357.

4. Van Bortel LM, Laurent S, Boutouyrie P, et al. Expert consensus document on the measurement of aortic stiffness in daily practice using carotid-femoral pulse wave velocity. J Hypertens. 2012;30:445-448.

5. Baulmann J, Nürnberger J, Slany J, et al. [Arterial stiffness and pulse wave analysis]. Dtsch Med Wochenschr. 2010;135 Suppl:4-14. German.

6. Wilkinson IB, McEniery CM, Schillaci G, et al. ARTERY Society guidelines for validation of non-invasive haemodynamic measurement devices: Part 1, arterial pulse wave velocity. Artery Res. 2010;4:34-40.

7. Quinn U, Tomlinson LA, Cockcroft JR. Arterial stiffness. JRSM Cardiovasc Dis. 2012;1(6)

8. Posokhov IN. Pulse wave velocity 24-hour monitoring with one-site measurements by oscillometry. Med Devices (Auckl). 2013;6:11-15.

9. Minyukhina IE, Lipatov KS, Posokhov IN. Analysis of 24-hour pulse wave velocity in patients with renal transplantation. Int J Nephrol Renovasc Dis. 2013;6:125-129.
10. Rogoza AN, Kuznetsov AA. Central aortic blood pressure and augmentation index: comparison between Vasotens ${ }^{\circledR}$ and SphygmoCor ${ }^{\text {B }}$ technology. Research Reports in Clinical Cardiology. 2012;3:27-33.

11. Koudryavtcev SA, Lazarev VM. Validation of the BPLab ${ }^{\circledR} 24$-hour blood pressure monitoring system according to the European standard BS EN 1060-4:2004 and British Hypertension Society protocol. Medical Devices: Evidence and Research. 2011;4:193-196.

12. Ageenkova OA, Purygina MA. Central aortic blood pressure, augmentation index, and reflected wave transit time: reproducibility and repeatability of data obtained by oscillometry. Vasc Health Risk Manag. 2011;7:649-656.

13. Bland JM, Altman DG. Statistical methods for assessing agreement between two methods of clinical measurement. Lancet. 1986;6 307-310.

14. Cronbach LJ. Coefficient alpha and the internal structure of tests. Psychometrika. 1951;16:297-334.

15. Luzardo L, Lujambio I, Sottolano M, et al. 24-h ambulatory recording of aortic pulse wave velocity and central systolic augmentation: a feasibility study. Hypertens Res. 2012;35:980-987.

16. Lovibond K, Jowett S, Barton P, et al. Cost-effectiveness of options for the diagnosis of high blood pressure in primary care: a modelling study. Lancet. 2011;378:1219-1230.

17. National Institute for Health and Clinical Excellence. Guidance. Hypertension: the clinical management of primary hypertension in adults: update of clinical guidelines 18 and 34. Available from: http:// www.nice.org.uk/guidance/CG127. Accessed January 23, 2014.

18. Baulmann J, Schillings U, Rickert S, et al. A new oscillometric method for assessment of arterial stiffness: comparison with tonometric and piezo-electronic methods. J Hypertens. 2008;26:523-528.

19. Jatoi NA, Mahmud A, Bennett K, Feely J. Assessment of arterial stiffness in hypertension: comparison of oscillometric (Arteriograph), piezoelectronic (Complior) and tonometric (SphygmoCor) techniques. J Hypertens. 2009;27:2186-2191.

20. Horváth IG, Németh A, Lenkey Z, et al. Invasive validation of a new oscillometric device (Arteriograph) for measuring augmentation index, central blood pressure and aortic pulse wave velocity. $J$ Hypertens. 2010;28:2068-2075.
Medical Devices: Evidence and Research

\section{Publish your work in this journal}

Medical Devices: Evidence and Research is an international, peerreviewed, open access journal that focuses on the evidence, technology, research, and expert opinion supporting the use and application of medical devices in the diagnosis, treatment and management of clinical conditions and physiological processes. The identification of novel

\section{Dovepress}

devices and optimal use of existing devices which will lead to improved clinical outcomes and more effective patient management and safety is a key feature. The manuscript management system is completely online and includes a quick and fair peer-review system. Visit http://www. dovepress.com/testimonials.php to read real quotes from authors. 